Ethiopian Journal of Environmental Studies \& Management 9(4): 443 - 449, 2016.

ISSN:1998-0507

doi: http://dx.doi.org/10.4314/ejesm.v9i4.5

Submitted: February 14, 2016

Accepted: June 29, 2016

\title{
CHANGE IN AIR TEMPERATURE OVER SUDAN AND SOUTH SUDAN WITH TIME AND STATION COORDINATES AND ELEVATION DURING THE LAST CENTURY
}

MOHAMED, H.A.

National Institute of Desert Studies, University of Gezira, Wad Medani, Sudan

Email: habiballa1954@gmail.com

\begin{abstract}
Annual mean air temperature for Sudan and South Sudan for the three periods 1900-1940, 1961- 1990 and 1981-2010 for 12 stations was analyzed with objectives of studying changes in air temperature over the area during the last century and also to study the linkages between mean, maximum and minimum air temperature on the one hand and latitudes, longitudes and elevations on the other hand. The data was obtained as normal data for each period from Sudan Meteorological Authority and other sources. The results showed an increase of about 0.60 degrees Celsius in the mean temperature of the 12 stations over the last century. The maximum temperature dropped in the second period by about 0.40 degrees Celsius and increased in the third period by about 0.35 degrees making almost no net change over the century. The minimum temperatures increased on the average by about 1.2 degrees since the turn of the last century and increased by about 0.32 degrees between the last two periods. The net increase in air temperature for the 12 stations over the last century was mainly a result of an increase in the minimum air temperature. The results also showed strong linkages between mean and minimum temperatures on one hand and longitudes on the other hand.
\end{abstract}

Key Words: Air temperature, Variation, Coordinates, Elevation, Sudan

\section{Introduction}

Importance of air temperature in our everyday life is well documented in the literature, (Mohamed, 2012). Air temperature determines the rate of biochemical reactions and there by affects the growth and development of plants. It affects the energy balances of surfaces, evapotranspiration, human comfort and almost every aspect of living organisms. That was probably the cause of early start of temperature measurements which goes back to the seventeenth century, so that systematic records in some areas of the world may be as old as two hundred years. Now days, the issue of a changing climate due to an observable rise in air temperature is causing a great global concern, (IPCC, 2013). The objective of this study is to find out whether air temperature over Sudan and South Sudan has changed over the last century and to find if there are linkages between air temperatures and the stations coordinates and elevations. The study made use of the normal climate 
temperature data where Normal in this context means a statistical average of a climate factor for thirty years; a period considered as being sufficient to yield reliable means.

\section{Methodology}

The study included a set of 12 stations representing each of the periods 1900/1940 (first period), 1961/1990 (second period) and 1981/2010 (third period). The stations are scattered a long and across the Sudan and South Sudan. The mean, maximum and minimum temperatures data for 1961/1990 and 1981/2010 was obtained from Sudan Meteorological Authority while data for 1900/1940 was obtained from Ireland temperature tables, (Ireland, 1948). Table 1 shows the stations and their latitudes, longitudes and altitudes.

Table 1: Meteorological stations used in the study periods 1900/1940, 1961/1990 and $1981 / 2010$ and their coordinates and elevations

\begin{tabular}{llll}
\hline City & Latitude $(\mathrm{N})$ & Longitude $(\mathrm{E})$ & Altitude (masl) \\
\hline W.halfa & 21.82 & 31.35 & 190 \\
Karima & 18.55 & 31.85 & 249 \\
Atbara & 17.7 & 33.97 & 345 \\
Khart. & 15.6 & 32.55 & 380 \\
Medani & 14.38 & 33.48 & 405 \\
Sennar & 13.55 & 33.62 & 418 \\
Malakal & 9.55 & 31.65 & 390 \\
Juba & 4.87 & 31.6 & 457 \\
Portsud & 19.58 & 37.22 & 2 \\
Kassala & 15.47 & 36.4 & 500 \\
Fasher & 13.63 & 25.33 & 730 \\
Elobied & 13.17 & 30.23 & 574 \\
\hline
\end{tabular}

The data was analyzed using Excel statistical package for descriptive statistics and for regression and correlations between the temperatures on the one hand and coordinates and elevations on the other hand.

\section{Result and Discussion}

\section{Time Course of Maximum Air Temperature}

Table 2 shows the average maximum air temperature for the 12 stations and for the three periods. The mean maximum air temperature was lower in the second period relative to the first period by about $0.40^{\circ} \mathrm{C}$, while that of the third period was higher by about the same value. This result showed almost no net difference in the 12 stations maximum temperature between the first period and the last period of the last century, but there was a difference of about 0.35 degrees between the last two periods.

Table 2: Maximum, minimum and mean air temperatures in ${ }^{\circ} \mathrm{C}$ for the 12 stations and for the three periods.

\begin{tabular}{lcccc}
\hline Temperature/Period & $1900 / 1940 *$ & $1961 / 1990$ & $1981 / 2010$ & Differences \\
\hline Maximum temperature & 36.05 & 35.65 & 36.00 & -0.05 \\
Minimum temperature & 20.12 & 20.97 & 21.29 & 1.17 \\
Mean temperature & 28.08 & 28.31 & 28.65 & 0.57 \\
\hline
\end{tabular}

*Long term means rather than normal 


\section{Time Course of Minimum Air Temperature}

Table 2 shows the average minimum air temperature for the 12 stations and for the three periods. It shows that the minimum air temperature in the last period was higher by about $1.17^{\circ} \mathrm{C}$ compared to the first period, while the difference between the third and second periods was 0.32 degrees, so that about $75 \%$ of the increase in the minimum temperature occurred in the first half of the last century. Similarly, an increase in minimum air temperature was reported by Makokha and Shisanya, (2010) for Nairobi near surface temperature. King'uyu et al. (2000) reported a night time rise in air temperature while investigation of surface temperature of Eastern Africa for the period 1939-1992.

\section{Time Course of Mean Air Temperature}

Table 2 shows that the across stations average of the mean air temperature in the last period was higher by about $0.57^{\circ} \mathrm{C}$ compared to the first period, and higher by about 0.34 degrees compared to the second period. Likewise, a global increase in air temperature of $0.8^{\circ} \mathrm{C}$ for the period 1880 onwards was reported by NASA (2015). However, NASA report stated that two thirds of the increase occurred from 1975 onwards. A warming range of the global temperature of 0.65 to $1.06^{\circ} \mathrm{C}$ was reported by the IPCC (2013) for the period 1880 and 2012. An increase of about $0.5^{\circ} \mathrm{C}$ in air temperature was reported for Japan between 1916 and 1965 (Landsberg, 1981).

Regression of Air Temperature versus Stations Coordinates and Elevations Mean Maximum Air Temperature

As can be seen from table $3 a$ and $b$, the maximum air temperature of the three periods was not significantly affected by any of the individual factors or their combinations. However, the combination of longitude and altitude together showed a clear linkage to maximum air temperature during the last two periods.

\section{Mean Minimum Air Temperature}

Table 3a shows that the minimum air temperature in the three periods was not significantly affected by latitudes, while it was significantly affected by altitudes and highly significantly affected by Longitudes. On the other hand table $3 b$ shows that the minimum air temperature was significantly affected by the combination of latitudes and altitudes and also that of the three factors, and highly significantly affected by the combination of latitudes and longitudes and that of the longitudes and altitudes. The effects on minimum air temperatures were therefore enforced by longitudes or their combinations

\section{Mean Air Temperature}

As shown in (Table 3a), neither latitudes nor altitudes had an effect on mean air temperature of their own and across periods. Longitudes showed strong effects on mean air temperatures in all periods with $(\mathrm{R})$ varying between $(0.66$ and 0.69$)$ and $(\mathrm{P})$ of $(0.01)$. With the exception of latitudes and altitudes together, all the combinations of factors showed significant effects on mean air temperatures during all periods. Longitudes and altitudes showed strong effects on mean air temperatures with (R) varying between ( 0.69 and 0.73$)$ and with (P) ranging from about (0.05 to 0.02 ).

Overall, regarding the individual factors, it is evident from this study that latitudes over Sudan and SS had little effects on air temperature variations. It is also evident that altitudes had effects only on minimum air temperature across periods. Longitudes on the other hand showed strong effects on minimum and 
mean air temperatures across periods. The combination of factors, and with exception of the effects on maximum air temperature which were not significant, showed strong effects on both minimum and mean temperatures and across periods. The greatest influences were those exerted on minimum and mean temperatures across all periods by longitudes, latitudes and longitudes, longitudes and altitudes and by the three factors.

Table 3a: Coefficient of correlation (R), standard error, (SE) and significance, $(\mathrm{P})$ for the regression of each factor on mean, minimum and maximum temperatures for the three periods

\begin{tabular}{|c|c|c|c|c|c|c|c|c|c|}
\hline Parameter/Temp. & \multicolumn{3}{|c|}{$1900 / 1940$} & \multicolumn{3}{|c|}{$1961 / 1990$} & \multicolumn{3}{|c|}{$1981 / 2010$} \\
\hline Latitude & $\mathrm{R}$ & SE & $\mathrm{P}$ & $\mathrm{R}$ & SE & $\mathrm{P}$ & $\mathrm{R}$ & SE & $\mathrm{P}$ \\
\hline Max. & 0.13 & 1.6 & 0.68 & 0.12 & 1.63 & 0.69 & 0.13 & 1.66 & 0.68 \\
\hline Min. & 0.00 & 2.1 & 0.98 & 0.08 & 1.80 & 0.79 & 0.10 & 1.65 & 0.74 \\
\hline Mean & 0.08 & 1.40 & 0.80 & 0.13 & 1.33 & 0.68 & 0.15 & 1.28 & 0.62 \\
\hline Longitude & & & & & & & & & \\
\hline Max. & 0.10 & 1.62 & 0.73 & 0.23 & 1.60 & 0.45 & 0.30 & 1.59 & 0.32 \\
\hline Min. & 0.80 & 1.24 & 0.001 & 0.82 & 0.68 & 0.0009 & 0.76 & 1.06 & 0.003 \\
\hline Mean & 0.66 & 1.04 & 0.01 & 0.69 & 0.96 & 0.01 & 0.69 & 0.93 & 0.01 \\
\hline Altitude & & & & & & & & & \\
\hline Max. & 0.20 & 1.59 & 0.52 & 0.19 & 1.62 & 0.55 & 0.09 & 1.67 & 0.76 \\
\hline Min. & 0.54 & 1.76 & 0.06 & 0.58 & 1.49 & 0.04 & 0.57 & 1.36 & 0.05 \\
\hline Mean & 0.29 & 1.34 & 0.35 & 0.26 & 1.29 & 0.40 & 0.30 & 1.24 & 0.33 \\
\hline
\end{tabular}

Table 3b: Coefficient of correlation (R), standard error, $(\mathrm{SE})$ and significance, $(\mathrm{P})$ for the regression of combination of factors on mean, minimum and maximum temperatures for the three periods

\begin{tabular}{llllllllll}
\hline Lat. \& Long. & $\mathrm{R}$ & $\mathrm{SE}$ & $\mathrm{P}$ & $\mathrm{R}$ & $\mathrm{SE}$ & $\mathrm{P}$ & $\mathrm{R}$ & $\mathrm{SE}$ & $\mathrm{P}$ \\
\hline Max. & 0.15 & 1.69 & 0.90 & 0.24 & 1.68 & 0.75 & 0.31 & 1.68 & 0.62 \\
Min. & 0.84 & 1.20 & 0.004 & 0.84 & 1.04 & 0.003 & 0.77 & 1.10 & 0.01 \\
Mean & 0.67 & 1.09 & 0.06 & 0.70 & 1.00 & 0.04 & 0.69 & 0.98 & 0.05 \\
Lat.\&Alt.. & & & & & & & & & \\
Max. & 0.36 & 1.60 & 0.53 & 0.34 & 1.63 & 0.56 & 0.24 & 1.71 & 0.75 \\
Min. & 0.66 & 1.66 & 0.07 & 0.65 & 1.46 & 0.08 & 0.62 & 1.36 & 0.10 \\
Mean & 0.31 & 1.41 & 0.63 & 0.26 & 1.36 & 0.71 & 0.30 & 1.31 & 0.64 \\
Long. \& Alt. & & & & & & & & & \\
Max. & 0.37 & 1.59 & 0.50 & 0.51 & 1.49 & 0.25 & 0.49 & 1.53 & 0.27 \\
Min. & 0.80 & 1.31 & 0.009 & 0.82 & 1.08 & 0.005 & 0.77 & 1.10 & 0.01 \\
Mean & 0.69 & 1.06 & 0.05 & 0.73 & 0.95 & 0.02 & 0.72 & 0.95 & 0.03 \\
Three param. & & & & & & & & & \\
Max. & 0.51 & 1.56 & 0.46 & 0.62 & 1.44 & 0.24 & 0.57 & 1.53 & 0.32 \\
Min. & 0.85 & 1.20 & 0.01 & 0.85 & 1.05 & 0.01 & 0.79 & 1.11 & 0.03 \\
Mean & 0.69 & 1.13 & 0.13 & 0.74 & 1.00 & 0.08 & 0.72 & 1.00 & 0.09 \\
\hline
\end{tabular}

Figures $1 \mathrm{a}, \mathrm{b}$ and $\mathrm{c}$ show the linear regression between mean air temperatures and longitudes for the three periods. The correlations were all significant. In fact the three equations demonstrated clearly the increase in mean annual temperature from the beginning of the century and onwards. For example at longitudes 35 the expected mean temperatures are 28.88, 29.07 and 29.39 for the three periods respectively, giving an increase in mean annual temperature of about $0.51^{\circ} \mathrm{C}$. 


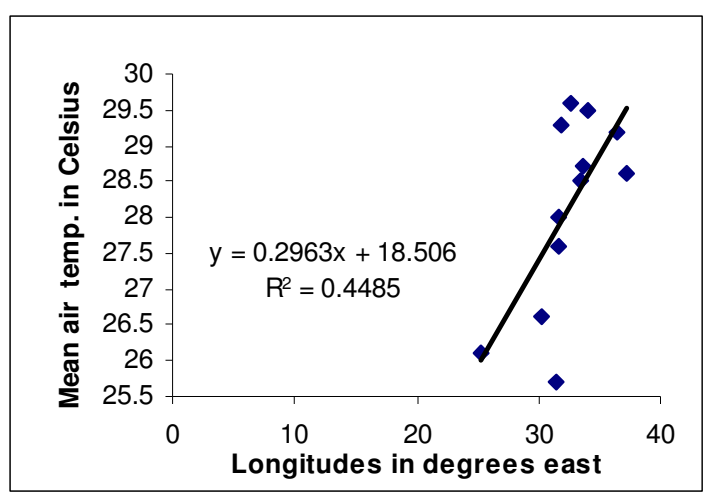

Figure 1a: Mean temperature for 12 stations for $1900 / 1940$ vs. longitudes

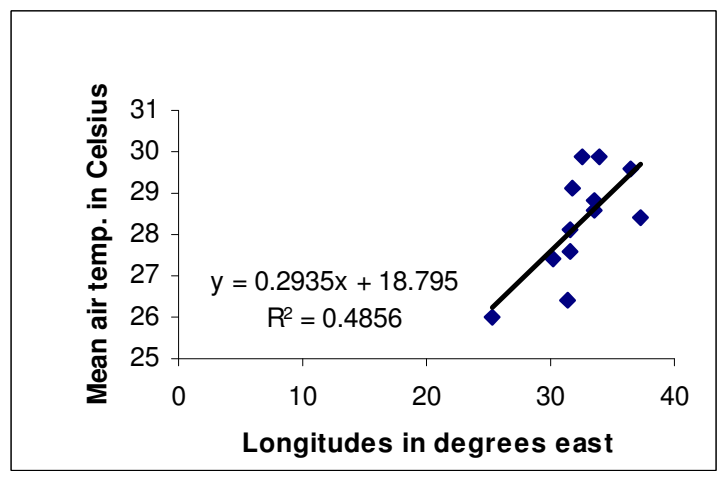

Figure 1b: Mean temperature for 12 stations for $1961 / 1990$ vs. longitudes

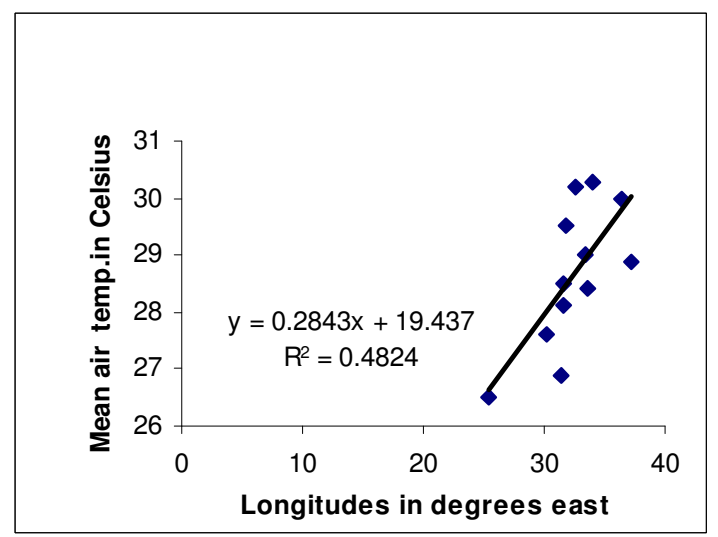

Figure 1c: Mean temperature for 12 stations for $1981 / 2010 \mathrm{vs}$. longitudes
Figures $2 \mathrm{a}, \mathrm{b}$ and $\mathrm{c}$ show the linear regression between minimum air temperatures and longitudes for the three periods. The correlations were all highly significant. In fact the three equations demonstrated clearly the increase in minimum annual temperature from the first period and onwards. For example at longitudes 35 the expected minimum annual temperatures are $21.49,22.17$ and $22.32^{\circ} \mathrm{C}$ for the three periods respectively, giving an increase in minimum annual temperature of about $0.83^{\circ} \mathrm{C}$. Figures $3 \mathrm{a}, \mathrm{b}$ and $\mathrm{c}$ and in spite of the deviating Portsudan point show a clear linear trend between maximum air temperatures and longitudes for the three periods. Although weak, the correlations and significances are increasing with time from the first period and on wards. The three equations demonstrated an increase in maximum annual temperature from the first period and onwards. For example at longitudes 35 the expected maximum annual temperatures are $36.19,35.93$ and 36.41 for the three periods respectively, giving an increase in maximum annual temperature of about $0.23^{\circ} \mathrm{C}$. Similar correlations were developed for various climatic elements as for the Piche evaporation, (Mohamed, 2015) and rainfall, (Diskin, 1970).

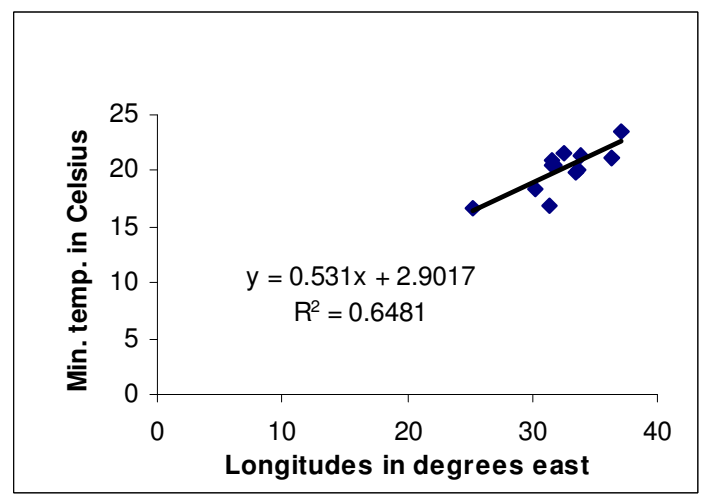

Figure 2a: Minimum temperature for 12 stations for 1900/1940 vs. longitudes 
Change in Air Temperature over Sudan and South Sudan................MOHAMMED, H.A.

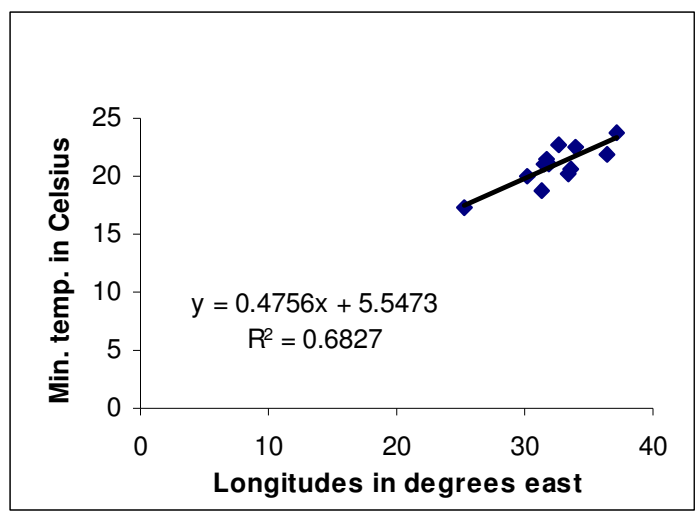

Figure 2b: Minimum temperature for 12 stations for $1961 / 1990$ vs. longitudes

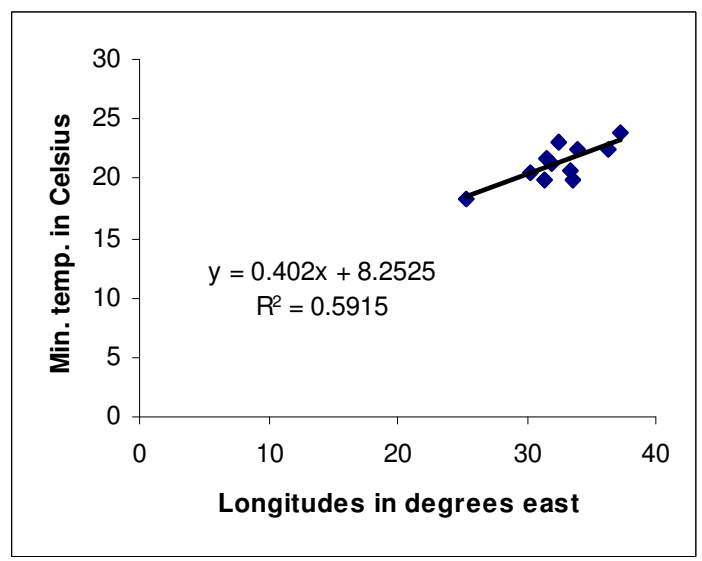

Figure 2c: Minimum temperature for 12 stations for $1981 / 2010$ vs. longitudes

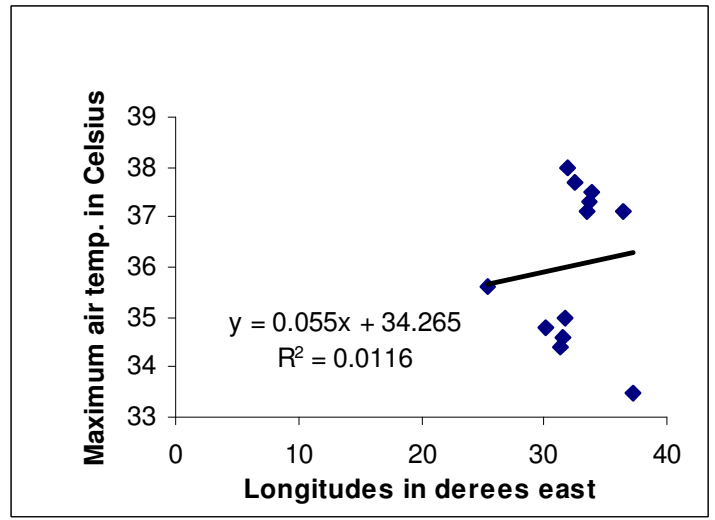

Figure 3a: Maximum temperature for 12 stations for $1900 / 1940$ vs. longitudes

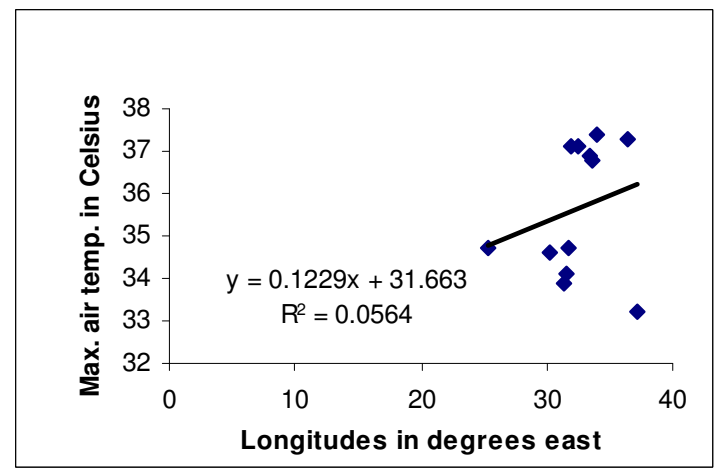

Figure 3b: Maximum temperature for 12 stations for 1961/1990 vs. longitudes

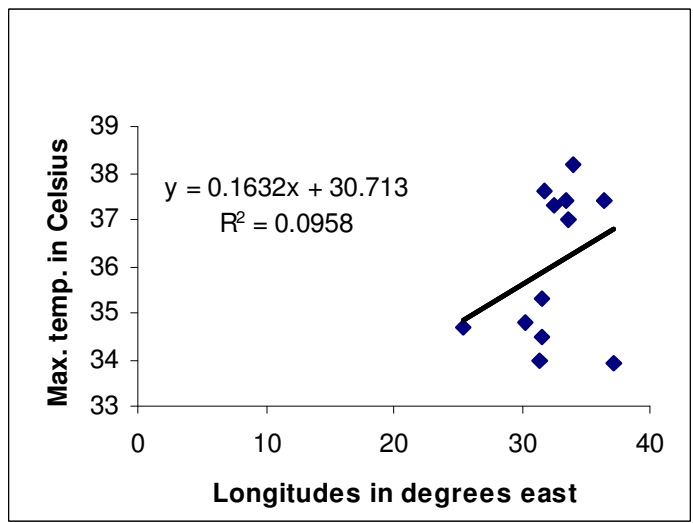

Figure 3c: Maximum temperature for 12 stations for 1981/2010 vs. longitudes

\section{Conclusion}

In conclusion the study which was based on almost reliable normal or long term data for three periods and in spite of ten years overlap between the last two periods showed that the surface mean temperature over Sudan and South Sudan increased substantially over the last century. It showed that the increase in the mean was attributed mainly to an increase in minimum air temperature. The study showed that the surface temperatures, in particular the mean and minimum temperatures are strongly correlated to longitudes and can be estimated using simple equations. The increase in surface temperature confirms the global rise in temperature reported by 
the IPCC, (2013).Since such increase affects the dynamics of the atmosphere; it will be reflected on many aspects of life including agriculture, environment, health and human comfort. The various sectors of concern in the country should therefore take the lead and address nationally the issue of warming in as far as the future dictates.

\section{References}

Diskin, M.H. (1970). Factors affecting variation of mean annual rainfall in Israel. Bulletin of the International Association of Scientific Hydrology, V15, 4:41 - 49.

IPCC (2013). Climate change2013: The Physical Science Basis. Summary for policy makers. In: Contribution of working group 1 to the fifth assessment report of the International Panel on Climate Change. http://www.ipcc.ch

Ireland, A. W. (1948). The climate of the Sudan, pp. 62 -83.In: Agriculture in the Sudan. Tothill, J.D. (ed). Oxford University Press, London

King'uyu, S.M., Ogallo, L.A. and Anyamba, E.K. (2000). Recent trends of minimum and maximum surface temperatures over Eastern Africa. J. Climate, 13:2876-2885.
Landsberg, H.L. (1981). General Climatology, 3 (edit.). Elsevier Scientific Publishing Company. Amsterdam-Oxford-New York

Makokha, G.L. and Shisanya, C.A (2010). Trends in mean minimum and maximum near surface temperature in Nairobi City, Kenya. Advances in Meteorology, Article ID 676041,6 pages http://dx.doi.org/10.1155/2010/676 $\underline{041}$

Mohamed, H.A. (2012). A simple thermal zonation of the Sudan: Sudan J. Des. Res., 4(1):1- 15.

Mohamed, H.A. (2015). Correlating annual Piche evaporation over Sudan and South Sudan to latitudes, longitudes and altitudes. Ethiopian Journal of Environmental Studies and Management, 8(3): 301-307. doi:http://dx.doi.org/10.4314/ejesm v8i3.7

NASA (2015). NASA Goddard Institute for space studies. Surface temperature analysis. Accessed September 2015. http://earthobservatory.nasa.gov.Fe atures/World of change/decadal temp.php. 